\title{
Who Cares About the Children of Prisoners in New Zealand? A Journey from Research to Practice
}

\author{
Liz Gordon
}

Before 2009, little research had been undertaken in New Zealand on the situation of the children of prisoners. Agencies such as Pillars Inc, a charity supporting these children, looking to undertake evidencebased practice, were forced to rely on models imported from other countries, especially the United States. This is despite the fact that New Zealand has a high level of imprisonment, at 193 per 100,000, approximately one third higher than Australia. In response to this, Pillars sought and received funding for a two-year research study and interviewed 368 men and women in nine prisons, and 72 families of prisoners (with the families, at least one caregiver, and sometimes a child, interviewed). Reports were produced on the findings in 2009 and 2010, and in 2011 a further report considered the implications for research and practice. As well, a practice manual was produced, along with resource kits for teachers and GPs. A large number of seminars and report-back meetings were held with government agencies, and a report was commissioned by Te Puni Kokiri, the Ministry of Māori Development, on the Māori data, which constituted half of the overall data. Subsequently, a number of further opportunities for research and dialogue have emerged. This article reports the core findings of the study: that the children of prisoners are not doing well, and that social support and justice agencies, whilst often having good intentions, contribute to this through poor, absent or inappropriate practices. The article concludes with a discussion of the impact of this research programme on policy and practice in New Zealand.

\section{Introduction: 'Not Our Crime - Still Our Sentence'1}

While criminal punishment is a highly individual process, with each judicial pronouncement tailored precisely to the perceived level of guilt, culpability and moral opprobrium allowed within the penal code, its effects ripple well beyond the sentenced person. As a person stands in the dock, awaiting sentence for a crime, the process has already begun that infuses judicial punishment into all areas of the lives of the family, and especially the children. The social reality is that the children of prisoners receive a comparable sentence for their parents' crime; a form, perhaps, of social incarceration.

1 Slogan used by Pillars Inc (<www.pillars.org.nz>) in association with NZ Children of Prisoners Week, 2012. 
The literature of the effects of parental incarceration on children is relatively new, emerging in the 1990s, partly in response to growing rates of imprisonment, ${ }^{2}$ most notable in the United States. ${ }^{3}$ Webster and Doob, writing about the large numbers of prisoners in that country, note that 'the increases have been unrelenting and massive in nature', ${ }^{4}$ driven by 'no tolerance' policies relating to drug offences in particular, and affecting persons of colour disproportionately. Western and Pettit provide an excellent overview of the problem seen within a social context of high levels of inequality:

The social inequality produced by mass incarceration is sizeable and enduring for three main reasons: it is invisible, it is cumulative and it is intergenerational. The inequality is invisible in the sense that institutionalised populations commonly lie outside our official accounts of economic well-being ... As a result, the full extent of the disadvantage of groups with high incarceration rates is underestimated. The inequality is cumulative because the social and economic penalties that flow from incarceration are accrued by those who already have the weakest economic opportunities. Mass incarceration thus deepens disadvantage and forecloses mobility for the most marginal in society. Finally, carceral inequalities are intergenerational, affecting not just those who go to prison and jail but their families and children too. ${ }^{5}$

As the number of prisoners in many jurisdictions have grown, so too has pressure for effective responses. ${ }^{6}$ In the literature, the effects of imprisonment on the children are considered to be complex and involve multiple disadvantages, as described in the following study:

Although the pain of losing a parent to prison is tantamount in many respects to losing a parent to death or divorce, the children who remain 'on the outside' appear to suffer a special stigma. Unlike children of the deceased or divorced who tend to benefit from society's familiarity with and acceptance of their loss, children of the incarcerated too often grow up and grieve under a cloud of low expectations and amidst a swirling set of assumptions that they will fail, that they will themselves resort to a life of crime or that they too will succumb to a life of drug addiction. ${ }^{7}$

Research consistently finds poor outcomes for the children of prisoners. For example, in the United Kingdom, Murray found that the children

$2 \quad$ R Walmsley, World Prison Population List (10th ed, 2013) International Centre for Prison Studies <htttp://www.prisonstudies.org/sites/prisonstudies.org/files/>.

3 CF Hairston, Focus on Children with Incarcerated Parents: An Overview of the Research Literature. (Annie E Casey Foundation, 2007) 2.

4 C Webster and A Doob, 'America in a Larger World: The Future of the Penal Harm Movement' (2008) 7(3) Criminology \& Public Policy 473.

5 B Western and B Pettit, 'Incarceration and Social Inequality' (2010) 3(8) Daedalus 139 .

6 For example, see New York Initiative for Children of Incarcerated Parents Safeguarding New York's Children of Incarcerated Parents (The Osborne Association 2010).

$7 \quad$ P Allard and J Greene, 'Children on the Outside: Voicing the Pain and Human Costs of Parental Incarceration' (2011) Justice Strategies Tides Center, Inc $<$ www.justicestrategies.org $>5$. 
of prisoners 'are vulnerable to multiple types of social exclusion's and, in a later systematic review, Murray and his colleagues concluded that the children of prisoners have about twice the risk of poor outcomes compared to other children, although the causal effects are not clear. ${ }^{9}$ Further examination of this issue in the United States, via a comprehensive literature review, found that prisoners' lives are characterised by 'cumulative disadvantage', and that policies and programs often fail to understand or mitigate the effects of this process. ${ }^{10}$ In recent times, the literature has begun to focus a little on policies and practices to support the children of prisoners. For example, a recent study ${ }^{11}$ provides a critique of support offered by schools to the children of prisoners in one region of England and what services and approaches may better meet their needs.

The study reported on in this article provided the beginnings of a research journey undertaken by an NGO (Pillars Inc), to find out about the specific situation of children of prisoners in New Zealand. This agency, searching for evidence on which to base its practice, found at the time that there was no such evidence relating to New Zealand, to the indigenous context or to local policies. While reporting some of the findings of that study, undertaken between 2009 and 2011, this article is also about subsequent events. In essence, the research became a participant in other discourses and a changing political context. Less than five years on from the commencement of the project, the commissioning agency has been thrust to the forefront, awarded a range of honours and sits at the centre of crucial debates about the future of children's wellbeing, of the role of the prison and of social policy in this country.

\section{Pillars and the Search for Relevant Knowledge}

Pillars Inc is a New Zealand charity formed 25 years ago by Verna McFelin. Verna is still the Chief Executive of the charity. Around 30 years ago, her husband was arrested, charged and convicted of a serious crime and spent a number of years in prison. During that time, Verna and her four children followed him around from place to place, living near to the many prisons, and fighting for good access for herself and her children. ${ }^{12}$ Pillars was born from her own experiences of those times. Its focus is on helping the families, and especially the children of prisoners, to live good lives.

8 J Murray, 'The Cycle of Punishment: Social Exclusion of Prisoners and their Children' (2007) 7(1) Criminology and Criminal Justice 55.

9 J Murray, D Farrington, I Sekol and R Olsen, Effects of Parental Imprisonment on Child Antisocial Behaviour and Mental Health: A Systematic Review (Campbell Systematic Reviews, 2009).

10 J Arditti, Parental Incarceration and the Family: Psychological and Social Effects of Imprisonment on Children, Parents, and Caregivers (New York University Press, 2012).

11 J Morgan, C Leeson and R Dillon, 'How Can Schools Support Children with a Parent in Prison?' (2013) 31(3) Pastoral Care in Education 199.

12 Amanda Cropp 'Rough Justice for the Innocents?' (2013) < http://www.pillars.org. nz/images/stories/rough-justice-innocents.pdf>. 
In the 21st century, the key mantra of funding accountability in New Zealand has been that agencies must work from evidence-based practice. ${ }^{13}$ Verna's argument was that, in the absence of good quality research on the children of prisoners, she was forced to turn to other countries for her evidence base. However, New Zealand had unique differences, with its high Māori imprisonment rates, its much higher rates of incarceration than Australia (193 per 100,000 compared with 130) or the United Kingdom (148) and its much lower rates than the United States (716). ${ }^{14}$ A New Zealand study was seen to be essential, even though it would be difficult and costly. This provided the motivation for this research study.

Working with a research partner (the company now known as Pūkeko Research Ltd), Pillars sought and received funding from a Lotteries research fund for a project to examine the situation of the children of prisoners. Over two years, the study interviewed 368 prisoners about their own family of origin and current family experiences, as well as 72 families, including adult caregivers and sometimes their children.

The method and structure of the research was described in the first report. ${ }^{15}$ Ethical approval from a national health research ethics organisation was given to undertake interviews in prison and with the families and children of prisoners. The prisoners, all volunteers, were surveyed in small groups across nine different prisons including three women's prisons, over a two year period. The interview tool was developed specifically for what was expected to be a low-literacy population. Each question was colour-coded, and the facilitator would say, for example: 'the blue question reads ...', and prisoners would select the correct response. One or two helpers would walk around ready to assist anyone who appeared to be having difficulties, but the tool worked very well and few had problems.

Prisoners were asked to send a letter to the caregiver of any children, recruiting families for the project. As well, Pillars and other agencies were asked to identify families for potential recruitment. Families, typically the caregiver and older children, were interviewed using an interview schedule, and responses analysed using a qualitative research program.

The initial report, produced at the end of the first year of the study, introduced the notion that the children were, from an institutional perspective, largely invisible. ${ }^{16}$ Aspects of this invisibility, and what is surmised from the few available studies, was summarised in the following United States research, which focused on the effects of parental imprisonment on the children:

13 S Nutley, H Davies and I Walter, 'Evidence-based Policy and Practice: Cross-Sector Lessons from the United Kingdom' (2003) 20 Social Policy Journal of New Zealand $<$ https://www.msd.govt.nz/about-msd-and-our-work/publications-resources/ journals-and-magazines/social-policy-journal/spj20/evidence-based-policy-and practice-20-pages29-48.html>.

14 List of countries by incarceration rate, Wikipedia <http://en.wikipedia.org/wiki/ List_of_countries_by_incarceration_rate>.

15 L Gordon, Invisible Children (Pillars, 2009).

16 Ibid, 1. 
Little is known about what happens to children and families when parents are arrested and jailed. The few studies that are available seem to indicate that children whose parents are incarcerated are more likely than other children to:

- show developmental delays and gaps

- do poorly in school

- suffer emotional distress

- develop substance use disorders

- commit multiple serious delinquent acts

- be incarcerated themselves during their lifetimes.

But for the most part, children are ignored when their parents are arrested and incarcerated - by all of the divisions of the criminal justice and childserving systems. Little is known and even less is collected and recorded. ${ }^{17}$

The Pillars' study had a similar focus, but went further and examined how the children experienced multiple agency interventions in the justice and social sectors. If the children were experiencing negative effects from parental imprisonment, why weren't these effects mitigated by the work of social support agencies? The Pillars' research examined all aspects of being the child of a prisoner from the moment of arrest onwards. ${ }^{18}$ The findings of the research showed that the children were largely invisible to the agencies of justice, while they were ineffectively supported by social service and education agencies. These findings are described in the next two sections.

\section{A Interacting with Agencies of Justice ${ }^{19}$}

A number of the families interviewed in the Pillars' research witnessed, or were part of, traumatic arrest procedures by the police. Two of the arrest stories are outlined in short form below: ${ }^{20}$

It was 6am. The whole family Mum, Dad, grandparents and the two children were all asleep when police and dogs arrived. Everyone was required to wait outside while the house was searched, the children still half asleep. The older child was very embarrassed as we had just moved there and all the neighbours were watching.

It was [son's] twelfth birthday and he had a big day planned when around 30 members of the Armed Offenders Squad (AOS) swarmed into the house with four dogs. They shouted and yelled and they popped round corners with their guns. The [Dad] gave himself up and they did not even use handcuffs. The whole family was traumatised and in tears all day. (Parent)

The 'dawn raid' approach is reportedly not that unusual, and it is also the method most likely to catch not only the alleged offender but also other

17 CA Walker, Children of Incarcerated Parents (Child Guidance Foundation, 2005) 6.

18 The research involves a series of research reports. Gordon 2009, n 15; L Gordon 'The Children of Prisoners' (2010) Unpublished paper presented to the Prison Fellowship conference, Lower Hutt; L Gordon 'The Causes of, and Solutions to, Intergenerational Offending' (Pillars, 2011).

19 By this we mean the police, the courts and all Corrections services.

20 Quoted in Gordon 2010, above n 18, 3. 
family and children. A stakeholder interview with the New Zealand police revealed that officers are able to exercise significant discretion in how they go about arresting a person. There is no requirement for arresting officers to justify how they go about an arrest, nor to plan for or consider the situation of the children. In effect, the study found that the children were treated as if they did not exist during arrest procedures. More importantly, at the time of the interviews it was fairly evident that some children had not got over the effects of the trauma they suffered on that day. With very limited access to counselling or other supports, there was little chance of healing.

What stoked this ongoing trauma? In the children's minds, the small glimpses they had received of how the justice system worked did not give them confidence that their parent would be safe in the system. Some of the children worried a lot about their parent in prison, whether he or she was safe:

[My daughter] just carried on but [my son's] education has got worse. He just used to sit there and do nothing, was thinking about his Dad instead of doing any school work. (Parent) ${ }^{21}$

Some of the children in the study stated directly that they really hated the police as a result of these experiences, and at quite young ages some demonstrate oppositional behaviours towards them, as one eight-year-old succinctly put it: 'Fuck poll poll they are dicks'. ${ }^{22}$ Such behaviours, in turn, make the children more vulnerable to negative outcomes as they grow up:

One of my daughters hated the police for the harassment and for taking her dad away. She never really got over it. She started to go backwards very quickly; started to play up and act out and eventually ended up on drugs, trying to take her life several times. (Parent) ${ }^{23}$

The other agencies of justice, the courts and the prisons, are certainly no better equipped to deal with children than the police. During the first year of the study we interviewed a senior official in the Department of Corrections who explicitly stated that prisons should not become places that are attractive to children, in case they make it more likely that children will want to offend. Although this view was officially denied by others as policy, it came at a time when visiting rooms in prisons around the country had been stripped of their toys and vending machines, and security rules had been tightened. A child was not able, and remains unable in early 2015, to bring in to a prison a picture painted for the parent, school work or indeed anything at all. Babies are allowed one bottle and one nappy.

In short, the process of visiting a parent in prison was revealed as very unpleasant in the study. Children talked of 'stone-faced guards' ${ }^{24}$ in some places, although others were not so bad. However children got bored in the

21 Gordon, above n 15, 56.

22 Ibid, 51.

23 Ibid, 47-48.

24 Ibid, 36. 
sterile visiting areas and the punitive atmosphere was very off-putting. As one of the parents remarked:

You do feel like you are doing something wrong. They need to be not so arrogant. They say the words that they have to say. They need to not class everyone as if they are doing something wrong. (Parent) ${ }^{25}$

Our research over two years revealed that the agencies of justice aggravated poor outcomes for children in a wide range of ways. The damage that is caused to them might appear to be 'collateral', in that it is largely (if not completely) unintended, but it is just as potent as direct damage. ${ }^{26}$ The oppositional stance, in particular, that children adopt towards police and prison, combined in adolescence with poor educational engagement and unresolved emotional difficulties was, in a number of cases, a recipe for a very direct route to intergenerational imprisonment.

Other work ${ }^{27}$ has examined how the judicial system discriminates against Māori through the selective exercise of discretion. For example, an analysis of the Māori data collected for the Pillars study ${ }^{28}$ lists multiple instances of poor engagement and often frightening events experienced by the tamariki (children), within police procedures and the prison system. These instances tend to drive the children to anger and into oppositional behaviour.

\section{B Interacting with Agencies of Social Support ${ }^{29}$}

It might be argued that the agencies of justice have no duty of care towards the children of prisoners, although the opposite position can also be justified. It is more difficult to explain the findings of our work that the health, education and social wellbeing of the children of prisoners was significantly impaired, affecting their ability to develop into well-balanced adults.

In particular, the Pillars study found that many, indeed nearly all, the children had significant identifiable but untreated physical and emotional health problems that affected their wellbeing. There is a growing literature on this point, with similar findings across nations and from study to study. For example, an earlier Australian paper notes:

The impacts of parental imprisonment on children can result in behavioural and emotional responses including fear and anxiety, sadness, and physical

25 Ibid, 34.

26 J Hagan and R Dinovitzer, 'Collateral Consequences of Imprisonment for Children, Communities, and Prisoners,' in M Tonry and J Petersilia (eds) Prisons (Crime and Justice: A Review of Research, Vol 26, University of Chicago Press, 1999) 121.

27 M Jackson, Maori in the Criminal Justice System. Unpublished paper (1988); and K Workman, 'Redemption Denied: Aspects of Over-representation of Maori in the Criminal Justice System' (Paper presented at the Justice in the Round Conference, University of Waikato, 18-20 April, 2011).

28 L Gordon, The Māori Children of Prisoners (Te Puni Kokiri, 2011).

29 In our research these included Work and Income, Education, Health and Related Agencies. 
symptoms including increased health problems and regressive behaviour such as bed-wetting. ${ }^{30}$

The 2009 Pillars study found similar effects among children of similar ages across the whole study. It therefore hypothesised ${ }^{31}$ a 'stage theory' approach to emotional harm - that children had different health effects arising from parental imprisonment at different ages. At the same time as the Pillars study was proceeding, the National Health Committee (an independent government quango) was producing a report making almost exactly the same point. ${ }^{32}$ The Invisible Children report outlined the process from nightmares, clinginess and screaming, to anger, bedwetting, upset and hyperactivity, to further forms of emotional upset and self-harm in adolescence:

Both the children can get quite angry. My daughter can get quite sad sometimes too. My son doesn't show it if he's sad. I think his anger is like ... for every emotion he'll just use anger ... he'll actually go out and punch fences and stuff. My daughter has problems with bulimia, cutting herself, harder drugs, drink driving, nightmares, loss of confidence and lack of respect for authority. I kind of class [my son's] drugs and alcohol as self harm ... to me that's self harm. And wandering around in the middle of the night, wasted, alone, that kind of stuff ... Just putting yourself in dangerous situations and no regard for your safety whatsoever really. (Parent) ${ }^{33}$

In reality, few of the children received any help for their many problems. The study noted that the children's health problems seemed invisible in the system and, more particularly, it appeared that the problems these children demonstrated were actually 'normalised' by health services. ${ }^{34}$ That is, it was impossible to explain why the problems identified in the research, time and time again, remained untreated by health services, when free services were available to many of these families. The research interviewed health stakeholders, but was unable to get any clear answers to this question. The first report notes:

The Ministry [of Health] interview concluded with a clear view that there were many service gaps to fill, and while this was an important area, it was not currently on the agenda. We were left with the impression that the structure of the health system seems to make any kind of integrated response extremely difficult. The Ministry also discussed current work on conduct disorders, and noted that the problem of hard to reach families needed to be turned around, and seen as a problem of hard to reach services. ${ }^{35}$

30 A Cunningham, Forgotten Families - the Impacts of Imprisonment (Australian Institute of Family Studies, 2001).

31 Gordon above $\mathrm{n} 15$.

32 National Health Committee, Health in Justice Kia Piki te Ora, Kia Tika! Improving the Health of Prisoners and their Families and Whannau (Wellington: National Health Committee, 2010).

33 Gordon, above n 15, 46-50.

34 See Gordon, above $\mathrm{n} 18$ and 28.

35 Gordon, above n 15, 49. 
One major gap identified in the reports was a general lack of counselling for the children. The improvement in the wellbeing of one child, who serendipitously lived next door to a counsellor who offered counselling at no charge, showed the value of such services: "[t]he improvements in the $14 \mathrm{yr}$ old have been because of her new friends, the talks with the counsellor (a neighbour) and having her grandmother there' (Parent). ${ }^{36}$

With most of the families surviving on welfare benefits, and in most cases these benefits keeping the families below the poverty line, ${ }^{37}$ few financial resources are available to the families to meet any costs of medical assistance such as counselling. One option available is through statutory intervention with Child, Youth and Family (CYF), where a child may be removed from the family due to concerns about his or her safety. This can unlock resources to help the child, as the following example demonstrates:

She's been in CYFs care for 2 months. Before that she went to 3 different schools and they didn't help, went to psychiatrists in Waikato, they were useless, went to Parentline and was getting counselling and they were useless. She was getting counselling once a month when she needed it every week. Not until she was put into CYFs care that the government started paying for it and she got the top quality. Before that I was doing it on my own. I had no idea who to contact, nobody would give me any names of anybody and I was just like, feeling around in the dark. (Parent) ${ }^{38}$

Despite the additional resources, the research showed that families in general, and prisoners in particular, strongly resist putting their children into state care. The reasons for this opposition were clear and consistent. There appears to be a general feeling that such care is yet another form of state imposition, of incarceration of a family member, onto the family.

While the health sector normalises emotional damage, the poverty-line incomes of benefit-led families requires particular attention. For families who have an income below the poverty line this means that their basic needs are rarely fully met. Even without the shadow of incarceration, such families struggle to provide even basic services to children. ${ }^{39}$ But there is no specific help to assist the children of prisoners to cope with the effects of parental incarceration. The existence of an incarcerated parent is not a criterion for additional support under the beneficiary rules. The Expert Advisory Group report summarises some of the effects of child poverty as follows:

New Zealand children living in poverty, especially Māori and Pasifika children, have poorer health and education outcomes than those living in households with average and higher incomes. For instance, compared with non-poor children, those living in poverty are:

- at a 1.4 times higher risk of dying during childhood

- more likely to die of Sudden Unexpected Death in Infancy

36 Gordon, above n 18, 28.

37 Expert Advisory Group, Solutions to Child Poverty in New Zealand: Evidence for Action (Children's Commissioner, 2012).

38 Gordon above $\mathrm{n}$ 18, 28.

39 Expert Advisory Group, above n 37. 
- three times more likely to be sick

- over two times more likely to be admitted to hospital for acute infectious diseases

- at least 1.5 times more likely to be hospitalised

- less likely to have fruit and vegetables

- more likely to skip breakfast and to consume fast food regularly

- hospitalised at a 5.6 times higher rate for injuries from assault, neglect or maltreatment

- less likely to participate in early childhood education

- less likely to leave school with NCEA level 2 - the entry level qualification to skilled employment. ${ }^{40}$

The position of most of the children of prisoners might be conceived as 'poverty plus'. Not only do most of them live in poverty, they often live with grandparents or other relatives, worry about their incarcerated parents and suffer from stigma and discrimination, feelings of loss and grief, shame and increased risk of abuse or neglect. ${ }^{41}$ Also, there is often a specific economic burden for the family, resulting either from debts accrued as a result of criminal activity (crime tends not to pay!), or from costs associated with the arrest and trial. One woman, attempting to continue to run a failing small business, noted that her husband is still costing a lot: she has had to buy him clothes, weekly phone cards, spend 'huge amounts' on petrol for visiting and has to continue to pay other costs he incurred. Despite these costs, 'Work and Income doesn't classify [him] as my partner. Even though we are still married ... Because he is in prison'. ${ }^{42}$ From the point of view of the benefit system, he does not exist, yet the costs he incurs are still significant.

Some families in the 2009 study faced a significant change in their circumstances as a result of parental imprisonment. One family had both parents working in good jobs before the husband went to prison. The economic effects have been devastating. Unable to cope with her family, work and the pressures that the crime and its aftermath have brought, the mother was forced to give up work and go on a benefit. She spoke of the loss of old habits, such as going to the movies, buying things on impulse and hopping in the car to go for a drive. In a sense they are coping: 'we do have food on the table; it's just not always the best food'. ${ }^{43}$

One area where the findings were very clear was in terms of education. At first, the research noted what seemed like a contradiction. On the one hand, the school, and in particular the child's main teacher, was often the first person the family turned to for help with the child. Several cases reported that the teachers had 'bent over backwards' to assist. Some were able to maintain confidentiality as well:

The bus driver knows. I made sure that only I was able to pick up my daughters from the bus for security reasons. I was concerned that the girls

\footnotetext{
40 Ibid, 15.

41 J Travis, E Cincotta and A Solomon, Families Left Behind: The Hidden Costs of Incarceration and Re-entry (Urban Institute Justice Policy Center, 2003).

42 Gordon, above n 15, 39

43 Ibid, 38.
} 
might be blacklisted, as we live in a small community. But the teacher has kept the information completely confidential. ${ }^{44}$

However, for a variety of reasons, the good, understanding relationships between teachers and caregivers tend not to lead to good educational outcomes. One reason is transience. Many of the children in the study moved school on a regular basis. Some were forced to move as a direct result of the crime:

The girls have had to move school because of their niece. She was in the same class. [My] daughter could hear across the classroom 'blah blah blah uncle ... blah blah blah rape ... blah blah her name'. (Parent) ${ }^{45}$

Over time, the achievement of the children of prisoners tends to fall. This is a near-universal process. Sometimes the causes are behavioural, such as the child who was excluded from school at age nine. In other cases, the children become bullies and are often bullied themselves. Others simply lose interest in schooling, and stop going: 'During the imprisonment the two oldest children turned away from school. They totally lost interest. The older boys were bunking from school. They didn't want to go' (Parent). ${ }^{46}$

In summary, the agencies of health, education and social services, while well-meaning in many cases, did not prevent the children of prisoners from poor outcomes. As a result, the children were often unprepared to take on the challenges of adolescence. Many ended up emotionally damaged, physically unwell, out of school or failing to learn effectively, with a strong sense of grievance and living with the effects of poverty. Because of a lack of effective interventions, factors that could have mitigated harm in early childhood were never put in place. The children of prisoners thus become 'sentenced' to poor outcomes, with the increased likelihood of themselves ending up in prison.

This last claim needs explanation. The research was unable to show directly that the children of prisoners are more likely to end up in prison than other children. The only way to demonstrate this, in research terms, is with a large, longitudinal study encompassing a general population of children. It was fortunate that the findings of such a study were available, which had factored in parental imprisonment as one indicator. The Christchurch Health and Disability Study (CHDS) was able to put together a table of outcomes at age 25 for its cohort. While the numbers of prisoners' children were small, the trends were quite clear across a range of indicators, as Table 1 (opposite) shows.

The findings of this table need to be read with caution, simply because only 33 people in the study cohort had had a parent go to prison before the study participant turned 15. But the difference in various trends outlined above is very clear between the two groups. The clearest trend is the relationship between parental imprisonment and child imprisonment. Although the numbers are small, the study shows that, for this cohort,

$44 \quad$ Ibid, 58.

45 Ibid, 57.

46 Ibid, 59 . 
Table 1 Associations between parental history of imprisonment (before age 15) and young adult outcomes by age 25 in the CHDS cohort. ${ }^{47}$

\begin{tabular}{|c|c|c|c|}
\hline PARENTAL HISTORY OF IMPRISONMENT & YES & NO & \\
\hline OUTCOME & $(\mathrm{N}=33)$ & $(\mathrm{N}=953)$ & $P$ \\
\hline \multicolumn{4}{|l|}{ Crime } \\
\hline$\%$ Property or violent offending (21-25 years) & 20.7 & 11.4 & NS \\
\hline$\%$ Arrested or convicted (21-25 years) & 17.2 & 7.4 & $<0.10$ \\
\hline \% Imprisonment (ever) & 15.6 & 1.6 & $<0.001$ \\
\hline \multicolumn{4}{|l|}{ Substance Use } \\
\hline$\%$ Nicotine dependence (25 years) & 48.3 & 22.1 & $<0.001$ \\
\hline$\%$ Alcohol dependence (21-25 years) & 6.9 & 5.3 & NS \\
\hline \% Illicit drug dependence (21-25 years) & 17.2 & 8 & $<0.10$ \\
\hline \multicolumn{4}{|l|}{ Mental Health } \\
\hline \% Depression/anxiety disorder (21-25 years) & 41.4 & 30.3 & NS \\
\hline$\%$ Antisocial personality disorder (21-25 years) & 13.8 & 2.7 & $<0.001$ \\
\hline$\%$ Suicide attempt (ever) & 18.2 & 8.1 & $<0.05$ \\
\hline \multicolumn{4}{|l|}{ Partnership/Parenthood } \\
\hline$\%$ Got pregnant/partner pregnant (by age 20 ) & 34.3 & 16.6 & $<0.01$ \\
\hline$\%$ Became natural parent (by age 20 ) & 24.1 & 7.4 & $<0.01$ \\
\hline$\%$ Inter-partner violence (25 years) & 13.8 & 8.3 & NS \\
\hline \multicolumn{4}{|l|}{ Education/Employment } \\
\hline$\%$ No educational qualifications (by age 25 ) & 37.5 & 12.3 & $<0.001$ \\
\hline$\% 12+$ months unemployment (21-25 years) & 20.7 & 8.9 & $<0.05$ \\
\hline$\%$ Welfare dependent (25 years) & 27.6 & 10.9 & $<0.01$ \\
\hline
\end{tabular}

the children of prisoners are 9.75 times more likely to go to prison than the children of non-prisoners. There are some factors, including the statistical variance likely with such low numbers, which make this figure uncertain.

Māori make up half of all prisoners, and have done since the 1980s, but the CHDS study took place in an area of New Zealand with a relatively low Māori population. Despite these difficulties, the figures in Table 1, which are the only figures available to us to effectively judge this matter, clearly demonstrate that the children of prisoners are much more likely, by the age of 25 , to have been imprisoned than the children of people who have never been to prison.

The other interesting element of Table 1 is that it reflects, in quantitative terms, the outcomes that the Pillars research observed qualitatively, in terms of health, mental health, education and family factors. The children of prisoners in the CDHS study achieved significantly worse results than the rest on all factors except family violence, anxiety/depression and alcohol dependence. Unless a very large study in the future examines this question longitudinally, New Zealand will never know exactly how

47 Data provided to the Pillars research team by Professor David Fergusson, CDHS Study, Otago School of Medicine. 
much more likely the children of prisoners are to enter prison than others. But the general levels of comparative poor health, education and other outcomes associated with that group are demonstrated clearly in this data. $^{48}$

\section{Research Making a Difference}

Almost as soon as the 2009 study was completed, and while the primary research was entering its second year, the findings of the Pillars research began to gain a lot of attention. In the second year, the team began to report its findings to stakeholders. With the National Health Committee's report also released in 2010, the health findings gained significant attention. Stakeholders across the board were interested in the initial outcomes. Further interest was sparked at the end of 2010 with a presentation to the well-attended Prison Fellowship conference. The release of the final report gained further attention in 2011.

Meanwhile, Pillars produced a research-led practice manual for those working with the children of prisoners, based on (and further reporting) the research findings. ${ }^{49}$ In 2011, Te Puni Kokiri, ${ }^{50}$ having discovered from the project's report-back to stakeholders that half the research data was Māori prisoners and children, asked for a re-analysis of the data using only Māori data, and the resulting report gained a large amount of attention across the state sector, as it gave impetus to the current focus on improving Māori outcomes. ${ }^{51}$

Some of the relationships were frustrating. A seminar at the Ministry of Health was poorly attended, while despite good contacts within the Ministry of Education, there was no opportunity to speak with policy or practice staff generally. The Ministry of Social Development, which encompasses the Child, Youth and Family agency as well as the Work and Income organisation that pays benefits, proved to be a huge and impenetrable organisation. Several meetings were held with Ministry staff, each one with different managers and different agendas. Nothing was promised and nothing happened. There was also a very pleasant but unproductive meeting with the New Zealand Police, where the issue of officers having complete discretion regarding arrest procedures was discussed, but no agenda for change was achieved.

Two seminars were held over two years at the Ministry of Justice, and these were attended by people across the State sector. By early

$48 \quad$ See also D Fergusson, NR Swain-Campbell, LJ Horwood, 'How Does Childhood Economic Disadvantage Lead to Crime?' (2004) 45(5) Journal of Child Psychology \& Psychiatry 956.

49 V McFelin, L Gordon L and L MacGibbon, Working with the Families and Children of Prisoners in Aotearoa / New Zealand: A Guide to Effective Practice to ensure Good Outcomes for the Children (Pillars, 2011).

50 Also known as the Ministry of Māori Development.

51 This report is Gordon, above n 28. Across all government agencies, and especially education and health organisations, improving Māori outcomes had a high priority at the time. 
2012, the team was invited to present a seminar at the Department of Corrections Head Office. This proved to be a watershed, but only because the Department was beginning to make its own changes, to reflect a need to bring down prison numbers. Since then, a number of changes have been made in that organisation, including halving the cost of phone calls from prison pay phones (one of the earliest findings was how expensive these were), and moving towards a range of family-friendly visiting options.

In short, the research has been well-received throughout the state sector and has been taken up and used by agencies, especially Corrections, which is in a time of change. While the research did not create the policy changes sweeping through that organisation, some of the changes clearly arose from the research.

Verna McFelin has received a national award and a national honour, and her work has been recognised by the Minister of Corrections in a recent ceremony. There was also a small amount of international honouring, as the Pillars research was featured at the 2012 Children of Prisoners Day at the United Nations in Geneva. The Quakers presented the research findings at that forum. Pillars is a relatively small NGO and cannot afford to present its work internationally.

\section{A Moving Forward - What is to be Done?}

Despite the widespread acceptance of the quality of the Pillars' research, and the relevance of the findings, little materially has changed as yet for the children of prisoners in New Zealand. Doing research to inform practice is one thing; getting the practices changed is another. It was noted above that one of the first outcomes of the research was a practice manual, which is available on Pillars' website. Further work has included the development of packs for education and health professionals including checklists of what to look for and how to act. Getting this to the right people, and then getting action, is problematic. Pillars has recently released a similar kit for defence lawyers on how to help their clients maintain good parenting through trials and imprisonment. A website for children and professionals, <www.justus.org.nz $>$, has been developed and provides educational resources about justice processes.

The changes in the Department of Corrections are providing an increased expectation that the barriers to prisoners being good parents even while in prison will be at least partially dismantled. But in other areas, things are getting not better but worse. For example, the Child Poverty Action Group has recently released a report ${ }^{52}$ demonstrating how the new work-test sanctions of the social security system are further impoverishing the most disadvantaged families:

Backing up the new paternalism of the welfare reforms has been the extensive use of financial sanctions to change the behaviour of beneficiary parents (although there is no evidence that their behaviour differs

52 D Wynd, Benefit Sanctions: Creating an Invisible Underclass of Children? (Child Poverty Action Group, 2013). 
significantly from other non-beneficiary parents). The changes have been marketed as 'improving outcomes' for children yet the intense pressure parents are under to take on paid work or face benefit cuts is doubtless placing enormous stress on both parents and children, especially at a time when employment growth has stagnated. ${ }^{53}$

Some wider debates have started in New Zealand: about income inequality, and child poverty, and the need to be less punitive and more democratic in state institutions, including schools and social services. ${ }^{54}$ A recent conference, Children in Crisis, brought people together from across all sectors to discuss and debate what is to be done. While Corrections policy appears to have moved on from the highly punitive approach of the past quarter of a century, giving hope that fewer people will end up in prison (and especially fewer Māori), the same sense of positive change and transformation is not yet evident across the other justice and social agencies of the state. The findings of the Pillars study make it clear that, until this wider change takes place, these agencies will continue to be part of the problem, not part of the solution, for the children of prisoners.

$53 \quad$ Ibid, 15.

54 L Gordon, 'The 486 Bus and Poverty: Habits of Mind and Body in a Segmented Society' (2014) 46(5) Educational Philosophy and Theory 1000-1004. 